\title{
OUTRO LOGOS, OUTRO ÉTHOS E OUTRA PRÁXIS PARA A CLÍNICA
}

\section{Débora Aymoré ${ }^{1}$}

Resenha da obra: Clínica e resistência: contribuições da racionalidade vitalista de Canguilhem ao campo da saúde Adriana Belmonte Moreira Associação Filosófica Scientiae Studia, São Paulo, 2019, $320 \mathrm{p}$.

A obra recém-lançada pela editora da Associação Filosófica Scientiae Studia defende a necessidade de uma revitalização da clínica médica partindo de uma análise filosófica, histórica e epistemológica capaz de suscitar a resistência às práticas de normalização da saúde. Para tanto, incita a incorporação dos valores, o que estaria na contramão da chamada dicotomia entre fato e valor ${ }^{2}$ e, neste sentido, da própria ciência livre de valores ${ }^{3}$. A questão da subordinação (ou não) da técnica à ciência é tratada ao longo da obra, concluindo-se em favor da aproximação da clínica à técnica, mais do que à ciência, o que a recoloca diante dos problemas humanos concretamente vivenciados na história de vida, tais como o sofrimento, a doença, o envelhecimento e a morte.

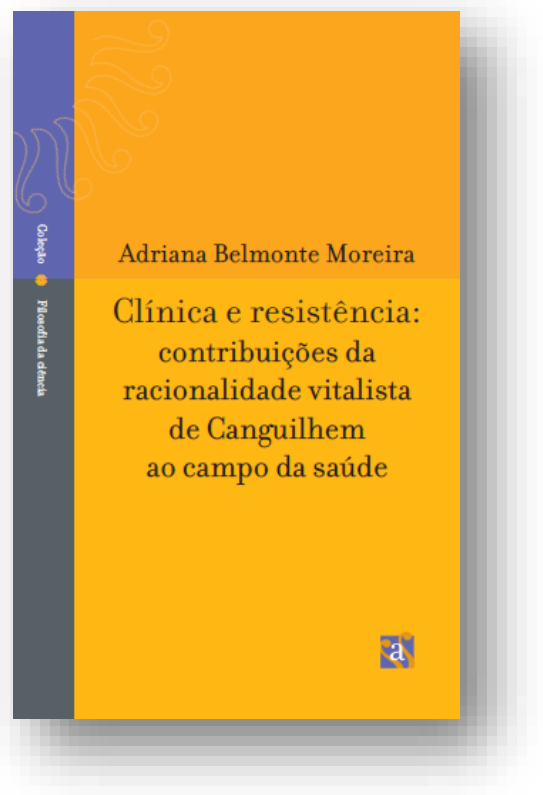

Neste sentido, Adriana Belmonte Moreira recupera o vitalismo materialista antimecanicista de Georges Canguilhem (1904 - 1995), elucidando que, juntamente com a concepção de biopoder de Michel Foucault (1926 - 1984), o século XIX testemunhou o estabelecimento da relação entre saber e poder nas práticas das instituições sanitárias, devido à ideia de subordinação psicossocial reconhecida na Biologia, na Psicologia e na Sociologia (cf. MOREIRA, 2019, p. 25). Ressalte-se, no entanto, que não se configura em Canguilhem a defesa de uma postura anticientífica ou antimedicina, mas antes uma rejeição de certos aspectos ideológico-repressivos direcionados ao fenômeno vital.

Os quatro capítulos em que a obra se subdivide apresentam como temas centrais:

O capítulo 1, "Medicina: uma arte enraizada na vida" refere-se à concepção de vida presente de modo esparso nas obras de Canguilhem. Quando sistematizada, é possível caracterizar a vida como espontânea, reativa e resistente às ameaças do meio (cf. MOREIRA, 2019, p. 47). Além disso, o autor questiona a definição de patológico como anormal, bem como a possibilidade de explicar a vida a partir dos modelos mecânico ou físico-químico (cf.

\footnotetext{
1 Professora substituta do Departamento de Filosofia da Universidade Federal do Paraná (UFPR), colaboradora e orientadora do Curso de Especialização em Estudos Culturais e Políticas Públicas (Poscult/ UNIFAP), membro da Associação Filosófica Scientiae Studia e dos grupos de pesquisa Núcleo de Estudos da Cultura Técnica e Científica (NECTeC/ UFPR), Ética e Filosofia Política (UEAP) e Estudos Interdisciplinares em Cultura e Políticas Públicas (UNIFAP).

2 PUTNAM, 2002; MARICONDA, 2006.

3 LACEY, 2005, 2008, 2010.
} 
MOREIRA, 2019, p. 56). O capítulo 2, “Arte da cura ou ciência das doenças?” inicia com a questão da anterioridade lógica e cronológica das técnicas em relação às ciências. A Medicina, neste sentido, está mais próxima da técnica, realizando a "força curativa natural", objetando-a como ciência das doenças. No capítulo 3, "Medicina, psicologia e normalização", Moreira aborda o paralelismo entre Medicina e Psicologia, ao analisar o anômalo biológico e o inadaptado social como representativos da potência vital. Apoiando-se em Foucault, Canguilhem considera que os escritos foucaultianos remetem ao nascimento histórico da norma social e não à normatividade da vida. Finalmente, o capítulo 4, "A revitalização da clínica", retoma os conceitos dos capítulos anteriores, propondo uma nova racionalidade, projetando a clínica como um exercício de resistência às práticas de normalização da vida e da saúde. Opondo-se, deste modo, à medicina social de tradição higienista.

\section{O VIVENTE}

Canguilhem identifica na Encyclopaedia universalis quatro concepções de vida, a saber: vida como animação, como mecanismo, como organização e como informação (cf. MOREIRA, 2019, p. 48), aproveitando-se apenas parcialmente delas para compor o seu vitalismo materialista antimecanicista. $\mathrm{O}$ vivente, para ele, é capaz de adaptar-se ativamente ao meio. E, assim, ao contrário da transposição da noção de meio da Física para a Biologia ocorrida no século XVIII, o vivente mantém sua interação com o meio e não sofre, deste modo, uma influência unidirecional do meio sobre si.

Ao analisar esta relação entre o vivente e o meio, Canguilhem refere-se à obra $A$ origem das espécies de Charles Darwin (1809 - 1882), consentindo à sua oposição às ideias de criação especial e de imutabilidade das espécies (cf. MOREIRA, 2019, p. 53). A mutação é uma característica imprescindível para a compreensão da vida, embora Canguilhem rejeite a transposição da concorrência vital para o âmbito social, própria da teoria evolucionista de Herbert Spencer $(1820-1903)$.

O vivente, desta maneira, “[...] se reproduz, se autorrepara, se autocura e se autorregula, sendo precisamente essa capacidade de reação e de resistência à morte, inerente a tudo o que vive, a origem da técnica médica" (MOREIRA, 2019, p. 58). O processo de cura deve evitar a submissão do organismo, pois a dominação a partir do exterior reduz a possibilidade de o organismo manter-se como centro de referência, como doador de sentido vital (cf. MOREIRA, 2019, p. 69).

Assim, o indivíduo saudável é normativo, enquanto o doente "[...] perdeu sua capacidade de instituir normas diferentes em condições adversas” (MOREIRA, 2019, p. 65). A cura, desta maneira, designa a possibilidade de reconquistar a metaestabilidade orgânica, pois, mais do que um mecanismo de conservação, permanece sempre o embate com o meio, resultando em influência recíproca capaz de "[...] transformá-lo e também transformar-se" (MOREIRA, 2019, p. 68).

A prática médica vincula-se à experiência da doença, “(...) que é menos um fato que um valor para aquele que adoece" (MOREIRA, 2019, p. 25). Canguilhem quer com isto ressaltar que está na relação estabelecida entre o médico e o paciente a possibilidade de diagnóstico e de cura que leve em conta a angústia e o drama específicos daquele indivíduo em sua história de vida.

Epistemologicamente, Canguilhem opõe-se ao mecanicismo e se filia à tradição vitalista de 
Bichat, responsável por distinguir as forças vitais das físico-químicas, concepção esta influente também nos trabalhos de Auguste Comte $(1798$ - 1857) e Claud Bernard (cf. MOREIRA, 2019 , p. 87). No entanto, ele rejeita o animismo, pois não haveria nem força vital, nem alma responsável por animar o organismo vivo.

A característica central do organismo, para Canguilhem, é a sua liberdade, na medida em que suas normas são internas, não necessitando, tal como as máquinas, de um operador ou um reparador (cf. MOREIRA, 2019, p. 99). Deste modo, a relação entre o vivente e a doença é um aspecto da dinâmica que o organismo estabelece com o meio, embora ambos, organismo e meio, influenciem-se reciprocamente.

\section{A DOENÇA}

Considerando a Medicina como arte da cura, Canguilhem a associa às técnicas, afirmando que sua característica própria seria a realização consciente da força da cura natural. Apenas quando associada à ciência biológica do normal é que a Medicina passou a ser caracterizada como a ciência das doenças (cf. MOREIRA, 2019, p. 112). Além disso, a própria ciência moderna passou, a partir do século XVIII, a definir o normal e o anormal experimentalmente e, segundo a concepção do médico escocês John Brown (1735 - 1788), a doença caracteriza-se por uma variação quantitativa para mais ou para menos, concepção esta difundida posteriormente por Claud Bernard (1813 - 1878) (cf. MOREIRA, 2019, p. 116).

$\mathrm{Na}$ obra Introduction à l'étude de la médicine expérimentale (1865), Bernard define a atividade experimental com o objetivo de identificação das leis dos fenômenos, o que operacionalizou a ideia positivista de que é necessário conhecer antes de agir (cf. MOREIRA, 2019, p. 126 127). Há, segundo Canguilhem, um exagero cientificista nesta valorização da experimentação, na medida em que, para ele, o laboratório é apenas um meio entre outros (cf. MOREIRA, 2019, p. 131).

Além disso, duas objeções se instauram: a primeira é a de que o indivíduo, quando colocado em situação experimental, pode não ser idêntico ao indivíduo em situação não experimental; e, a segunda é a de que se pode, com a experimentação, provocar alterações na doença que não ocorreriam quando ela se instaura espontaneamente (cf. MOREIRA, 2019, p. 141 - 142).

No entanto, para o ser humano, viver é conhecer e, assim, quando observada da perspectiva do indivíduo, "[...] a doença pode ser caracterizada como incapacidade de realizar certas tarefas, tornando imprecisa a fronteira entre o normal e o patológico” (MOREIRA, 2019, p. 150). Mas o doente nunca se engana, pois a doença se apresenta primeiramente para ele como uma “[...] sensação subjetiva de restrição normativa” (MOREIRA, 2019, p. 152).

Porém, esta perspectiva individual sobre a experiência da doença dificulta a identificação de um tipo biológico saudável, aderindo à concepção de multiplicidade normativa do vital. A saúde torna-se, assim, a capacidade de transformar o meio a partir do centro de referência individual (cf. MOREIRA, 2019, p. 159).

\section{A NOVA CLÍNICA: LIBERDADE E RESISTÊNCIA}

O discurso médico e psiquiátrico pode, no entanto, contribuir para o processo social de normalização dos indivíduos e é especialmente neste ponto que as reflexões de Foucault e de Canguilhem se encontram. Em Os anormais, Foucault afirma que o século XIX presenciou 
instituições comprometidas com a cura e a correção das anormalidades e em $A$ história da loucura, o autor acompanha a transformação do louco em doente mental por via discurso médico-jurídico (cf. MOREIRA, 2019, p. 159 - 162). Porém, ao contrário de Foucault, Canguilhem evidencia a experiência concreta do vivente e não a caracterização da norma social, uma vez que a medicina social higienista será a responsável pelo controle da saúde das populações e pela normalização da vida cotidiana (cf. MOREIRA, 2019, p. 164).

Na obra Em defesa da sociedade, Foucault identifica a transferência da preocupação do poder que, nos séculos XVII e XVIII, estava concentrada nos corpos individuais. Mas, desde o século XIX o Estado passa a preocupar-se com o vivo, originando a chamada biopolítica, fazendo com que o médico seja corresponsável por manter a saúde da população (cf. MOREIRA, 2019, p. 168 - 169).

Acompanhando o trabalho de Georges Freidman (1902 - 1977) sobre o maquinismo industrial, Canguilhem afirma a necessidade de repensar as relações de trabalho que se tornam outro meio com o qual o homem interage. Mais do que isso, os seres humanos adoecem, à medida que "[...] as normas capitalistas, suplantando as normatividades individuais e tolhendo as potencialidades humanas levam o operário à insatisfação e ao esvaziamento do sentido atribuído ao seu trabalho" (MOREIRA, 2019, p. 186). É preciso, assim, resistir à mecanização taylorista, o que possibilitaria a defesa biológica e social. A resistência prescreve, então, um retorno da subjetividade, pois ela resiste à racionalização econômica e à redução do ser humano à máquina (cf. MOREIRA, 2019, p. 187).

Canguilhem prescreve, então, para a clínica médica ou psicológica, o afastamento em relação à técnica de controle e de normalização dos indivíduos, rejeitando o modelo maquinal de corpo (cf. MOREIRA, 2019, p. 206). A Medicina e a nova ciência genética podem, assim, resvalar em uma extensão do controle sobre a vida, tornando o médico um membro do exercício da biopolítica que, ao normatizar a população, imprime a docilidade no sujeito, possibilitando a conformação passiva às normas externas a si (cf. MOREIRA, 2019, p. 217).

Deste modo, mesmo que a condição de doença favoreça uma relação assimétrica entre o médico e o paciente, a partir das ideias de Canguilhem é possível identificar a própria terapêutica como potencialmente direcionada à restauração e preservação da liberdade (cf. MOREIRA, 2019, p. 220). Portanto, a obra Clínica e resistência resulta em outro pensamento (logos) sobre a vida, opondo-se ao mecanicismo e à definição exclusivamente experimental da doença, em outra ética (éthos) capaz de levar em conta valores positivos da vida, bem como em outra metodologia para a clínica (práxis), capaz de assegurar a reação espontânea e a capacidade de resistência, o que incentiva o incremento da liberdade em sentido biológico, existencial e social.

\section{REFERÊNCIAS}

LACEY, H. Is science value free? V alues and scientific understanding. England: Routledge, 2005 [1999].

- Valores e atividade científica 1. 2 ed. São Paulo: Associação Filosófica Scientiae Studia/ Editora 34, 2008. 34, 2010.

Valores e atividade científica 2. São Paulo: Associação Filosófica Scientiae Studia/ Editora

MARICONDA, P. R. O controle da natureza e as origens da dicotomia entre fato e valor. 
Scientiae Studia, 4, 3, p. 453-472, 2006.

PUTNAM, H. The collapse of fact/value dichotomy and other essays. Cambridge/ Massachusetts/ London, England: Harvard University Press, 2002. 